\title{
'Alternative futures' of the Okavango Delta simulated by a suite of global climate and hydro-ecological models
}

\author{
P Wolski* and M Murray-Hudson \\ Harry Oppenheimer Okavango Research Centre, Private Bag 285, Maun, Botswana
}

\begin{abstract}
The natural resources of the Okavango Delta, a large wetland in semi-arid Botswana, form the basis of livelihoods of the local population and support economically important high-end tourism. The hydro-ecological system is dynamic at various time scales, responding to climate variability, and both flood and drought conditions have in the past put pressure on the system's users. Human-induced climate change can potentially exacerbate the effects of existing climate variability. In this paper, we present simulated future hydro-ecological conditions in the Okavango Delta generated by a step-wise modelling procedure. The outputs of three different global climate models are used to drive a suite of hydrological models. Lastly, a rule-based dynamic model relates hydroperiod conditions to vegetation assemblages. The simulated future conditions vary from much drier to much wetter than those recorded in the past. Models indicate that climatic change would result in change in both extent and distribution of the major ecotopes of the Okavango Delta. Importantly, the different ecotopes will be affected to varying degrees. The projected changes will have consequences for the wildlife-based management of the system. They will affect, for example, available grazing and migration/movement patterns of large herbivores, as well as fish. Such consequences can have rapid up-trophic level effects, ultimately leading to potentially substantial impacts on the economy. The main conclusion to be drawn is that management planning and land-use systems should be as flexible as possible.
\end{abstract}

Keywords: climate change, development planning, GCM, hydro-ecological modelling, wetland management

\section{Introduction}

The Okavango Delta is a large wetland located in semi-arid north-western Botswana. It is a largely pristine ecosystem with a very small anthropogenic footprint, and is recognised as a Ramsar site. The system is naturally variable: dry and wet conditions of duration from a year to 30 to 40 years have been recorded in the past (Mazvimavi and Wolski, 2006). Additionally, the system is subject to shifts in distribution of inundation resulting from active geomorphological processes: channel aggradation and avulsion, occurring at a variety of scales (McCarthy et al., 1993; McCarthy et al., 1992; Wolski and Murray-Hudson, 2007). Observations indicate that any change in the hydrological regime within any part of the system brings about transformation of the ecosystem. Vegetation change can be subtle, such as from sedgedominated floodplains to grass-dominated ones, or drastic: from papyrus plains to dry-land. Changes in vegetation propagate up trophic levels with the consequence of wildlife relocating to find suitable vegetation and environmental conditions.

Greenhouse gas emission-driven climate change is widely accepted as happening, and recognised as a factor of prominent importance for the future well-being of the global environment (IPCC, 2007). With the goal of stimulating thought and debate about its implications for wetland management, this paper presents preliminary results of modelling of the potential effects of future climate change resulting from anthropogenic global warming on the ecosystem of the Okavango Delta. It focuses on linking the hydrological regime under changing climate with ecosystem vegetation characteristics.

\footnotetext{
To whom all correspondence should be addressed.

+267 6861833; fax: +267 6861835;

e-mail:pwolski@orc.ub.bw
}

\section{Okavango Delta}

The Delta is a large, flood-pulsed wetland. Its hydrology has been frequently described in the literature (e.g. Wolski et al., 2006; McCarthy et al., 1998a; Dinçer et al., 1987), and therefore only the major characteristics are given here. The Delta is subject to a discrete annual flood pulse. The flood is primarily caused by the seasonal flood wave of the Okavango River, and local rainfall plays a lesser role: flooding is asynchronous with the local rainy season. As a result of inter-annual differences in local and upstream rainfall, as well as longer-term effects of surface-groundwater interactions within the Delta, the area of inundation displays strong inter-annual variability: over the period of record 1932-2000, annual minima varied between 3500 and $6000 \mathrm{~km}^{2}$, while the annual maxima were recorded at 6000 to $14000 \mathrm{~km}^{2}$ (McCarthy et al., 2004; Gumbricht et al., 2004). These dynamics cause spatial differences in hydroperiod (frequency, duration and depth of inundation), which are in turn associated with vegetation assemblages adjusted to the prevalent hydrological conditions. This association is traditionally expressed by distinguishing broad hydro-ecological units: permanent swamp, seasonal regularly inundated floodplains, seasonal occasionally inundated floodplains and dry-land (McCarthy et al., 2005).

\section{Previous work on modelling of ecological consequences of climate change in the Okavango Delta}

Since the Delta is a wetland ecosystem in an arid environment, it is clear that the ecological effects of climate change have to be looked at through changes in hydrological regime, as caused by rainfall and evaporation, rather than through changes in temperature only. Hydrological change was assessed by Wolski et al. (2002), who expressed climate-change effects through 
TABLE 1

Global climate models used in this and earlier studies on the Okavango

\begin{tabular}{|l|l|l|}
\hline Abbreviation & Institution & Reference \\
\hline HadCM3 & Hadley Centre, UK & Gordon et al. (2000) \\
\hline CCCma CGCM2 & Canadian Centre for Climate Research, Canada & Flato and Boer (2001) \\
\hline GFDL R30 & Geophysical and Fluid Dynamics Laboratory, USA & Knutson et al. (1999) \\
\hline
\end{tabular}

\begin{tabular}{|c|c|}
\hline \multicolumn{2}{|c|}{$\begin{array}{c}\text { TABLE } 2 \\
\text { Preliminary classification of main vegetation classes (or ecotopes) in the areas susceptible to flooding } \\
\text { in the Okavango Delta }\end{array}$} \\
\hline Class (ecotope) & Characteristic species \\
\hline Savannah & $\begin{array}{l}\text { Grasses: Schmidtia pappophoroides, Aristida meridionalis, Enneapogon cenchroides; } \\
\text { Herbs: Peschuel-loeschia leubnitzieae, Hermannia spp. } \\
\text { Woody spp (as shrubs): Combretum imberbe, Acacia erioloba }\end{array}$ \\
\hline $\begin{array}{l}\text { Flooded } \\
\text { Grasslands }\end{array}$ & $\begin{array}{l}\text { Grasses: Eragrostis rigidior, Eragrostis lappula, Urochloa mossambicensis, Digitaria spp, Cynodon dactylon } \\
\text { Sedges: Cyperus longus, Abildgaardia hispidula } \\
\text { Herbs: Sphaeranthus flexuosus, Nicolasia costata. Vernonia glabra }\end{array}$ \\
\hline Sedge-lands & $\begin{array}{l}\text { Grasses: Panicum repens, Brachiaria humidicola; Eragrostis inamoena, Setaria sphacelata, Sacciolepis } \\
\text { typhura, Acroceras macrum. } \\
\text { Sedges: Schoenoplectus corymbosus, Cyperus denudatus, Eleocharis variegata, Fuirena spp, Rhynchospora } \\
\text { holoschoenoides. } \\
\text { Herbs: Ludwigia stolonifera, Cycnium tubulosum }\end{array}$ \\
\hline Aquatics & $\begin{array}{l}\text { Grasses: Oryza longistaminata, Leersia hexandra, Brachiaria humidicola, Paspalidium obtusifolium; Miscant- } \\
\text { hus junceus } \\
\text { Sedges: Oxycarium cubense, Eleocharis dulcis; Pycreus nitidus. } \\
\text { Herbs: Nymphaea nouchalli, Nymphoides indica, Potamogeton thunbergii }\end{array}$ \\
\hline
\end{tabular}

spatially distributed change in hydroperiod. In a more recent study (ODMP, 2006) climate-change effects were expressed in terms of change in the lower envelope of flooding. Both those studies used outputs of the HadCM3 (for explanation of model acronyms, see Table 1) global climate model (GCM), and simulated considerably drier conditions that those observed in the past. Murray-Hudson et al. (2006) used outputs of three GCMs: HadCM3, CCCma CGCM2 and GFDL R30 (Table 1) routed through a set of hydrological sub-models to determine changes in hydroperiod, and consequently change in distribution of major ecosystem units. Future climate conditions as simulated by several GCMs were consistent in terms of future temperature fields, but were very different in terms of future rainfall. These differences resulted in the simulation of Okavango basin conditions which ranged from much drier, through similar, to much wetter than those observed in the past, depending on which GCM model was used. Consequently, major ecosystem changes were projected for the Delta corresponding to the extreme GCM outputs. To assess the ecosystem changes, Murray-Hudson et al. (2006) used a simple, static hydroperiod-ecosystem model to simulate the distribution of floodplain vegetation ecotopes. In this model, computational elements of the hydrological model were classified into different floodplain ecotopes based on average hydrological conditions (frequency and duration of inundation) simulated during a period of 15 years. Such an approach was based on earlier interpretive vegetation work by SMEC (1989), and was considered useful for indicative purposes. It did not, however, reflect the shorter-term dynamics of the hydroecological system. Field observations suggest that successional trajectories in floodplain vegetation assemblages respond relatively fast to change in hydroperiod conditions. Under seasonal flooding, dry savannah areas develop a flooded grassland assemblage in 1 to 2 flood seasons. If seasonal flooding continues ( 3 or more consecutive seasons) succession to a sedge-dominated assemblage, with different functions in the ecosystem, can occur. The 15-year averaging period used in the static model is therefore considered inappropriate for investigating hydrologydriven ecological trajectories in this system. A dynamic model is therefore being developed, a rule-based version of which is presented in this paper.

\section{Dynamic ecotope model}

In a subsequent ongoing study (Murray-Hudson, 2008), a structured, quantitative vegetation survey was performed, covering over 30 sites characterised by different hydroperiod. Hydroperiod was determined on the basis of a reconstruction of inundation history from a series of Landsat imagery (Wolski and Murray-Hudson, 2006). Analysis of the vegetation data is not yet complete. However, qualitative information and experience from the field permitted an initial coarse classification of distinct vegetation assemblages, presented in Table 2. These assemblages have geographically specific type areas which have been used to define their hydroperiod characteristics from the satellite image time series. Hydroperiod conditions which would result in a successional shift were defined based on field observations from the past 5 years, in which there have been increasing flood extents in the Delta. Based on these, a rule-based dynamic model of hydroperiod-vegetation relationships was developed. This model has the character of an expert system (a series of IF...THEN... statements), and is presented in Fig. 1. Calculations are performed on the basis of pixel-by-pixel characteristics of hydroperiod (number of months inundated) determined from the output of the suite of hydrological models.

In this paper we use the procedure and results of hydrological and climate-change modelling presented earlier by MurrayHudson et al. (2006), Wolski et al. (2006), Hughes et al. (2006) and Andersson et al. (2006). The procedure is summarised in Fig. 2. Future conditions are not simulated explicitly. Instead, a historical series of monthly rainfall and mean monthly tempera- 


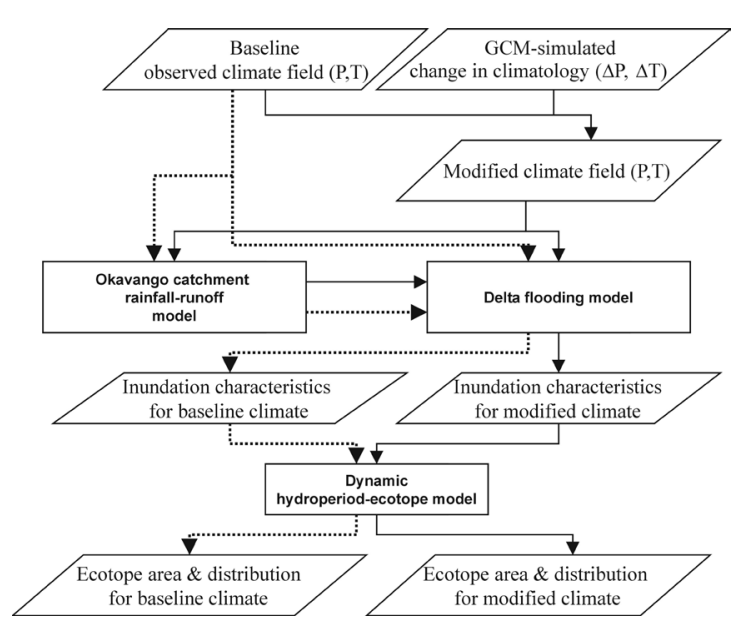

Figure 1

Dynamic model of hydrology-vegetation linkages in the Okavango Delta. ECO - current ecotope, DO - duration of inundation (in months) during given year, D1 - duration of inundation during previous year, D2 - duration of inundation two years earlier, etc.

tures is modified so as to reflect relative change simulated by the GCMs considered. Modification is applied to monthly values only - these are multiplied by a change factor obtained from a given GCM under a given greenhouse scenario and for a given future period. No effects on rainfall intensities at shorter times are considered. Eventual changes in persistence of rainfall and temperature conditions (duration and frequency of occurrence of dry/wet or cold/hot spells) are not taken into account. In this analysis three GCMs were used: HadCM3, CCCma CGCM2, GFDL R30 (Table 1). For hydrological modelling two models were used: the Okavango River basin model (Andersson et al., 2006), the output of which was used as input to the Okavango Delta model (Wolski et al., 2006). The latter model consists of two sub-models. The first is a semi-distributed sub-model representing the Delta using 8 large interconnected units, each simulated as a non-linear reservoir. The output of this sub-model consists of a time series of inundated area in each of the units. The second is a GIS sub-model which schematises each of the units by a grid of 1 by $1 \mathrm{~km}$ blocks. For each of the blocks a relationship between unit inundated area and inundation status is determined based on a time series of observed, satellite-derived inundation maps. This relationship is then used to translate simulated inundated area to inundation distribution. For the sake of brevity, we do not describe the models more extensively here, but refer the interested reader to the original sources.

\section{Results and interpretation}

The simulations were done for a combination of prognoses

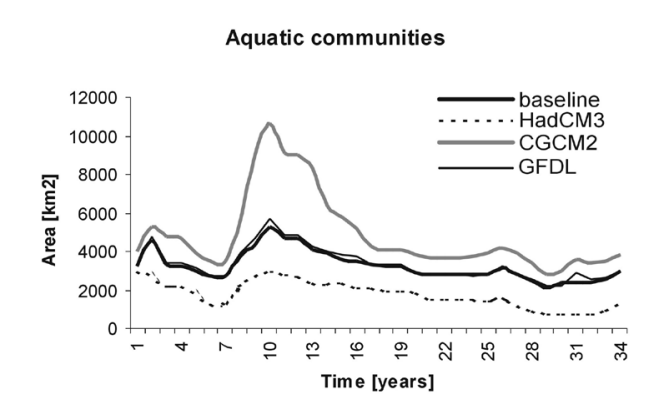

from $3 \mathrm{GCMs}$, for 2 greenhouse-gas scenarios and 3 different periods - in total 18 combinations. Analyses revealed that results for various GCMs suggest change in different directions (towards drier or wetter conditions), while differences between greenhouse gas scenarios are only in terms of magnitude of change, as are differences between various future time frames. Choice of a GCM is therefore of higher importance in assessing possible future hydro-ecological conditions in the Okavango Delta than the choice of greenhouse-gas scenario or time frame. Thus (and for the sake of brevity), we do not present the results of all combinations here. Instead we present results for one greenhouse-gas scenario (SRES B1), for one future period: 2020-2050, and for all 3 GCMs considered. The results of simulation are presented in Fig. 3 in the form of temporal variations in the areas of the ecotopes, while Fig. 4 presents spatial distributions of ecotopes.
Procedure for assessment of effects of climate change on the hydro-ecological system of the Okavango Delta. Dotted lines represent baseline simulations; solid lines represent simulations under changed climate.

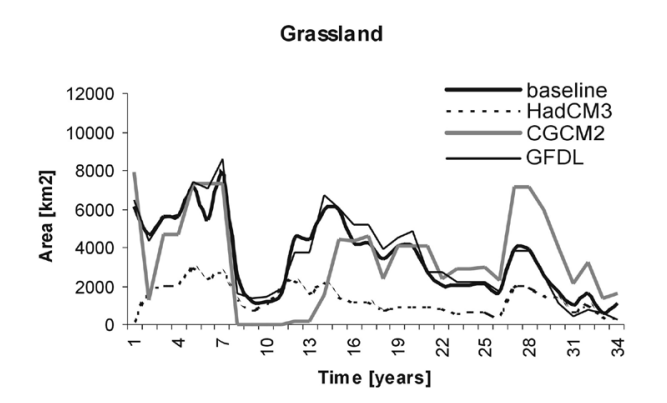

Figure 3

Area of the different ecotopes for climate predictions by various GC models and under baseline conditions. Year 1 of baseline corresponds to 1968. 

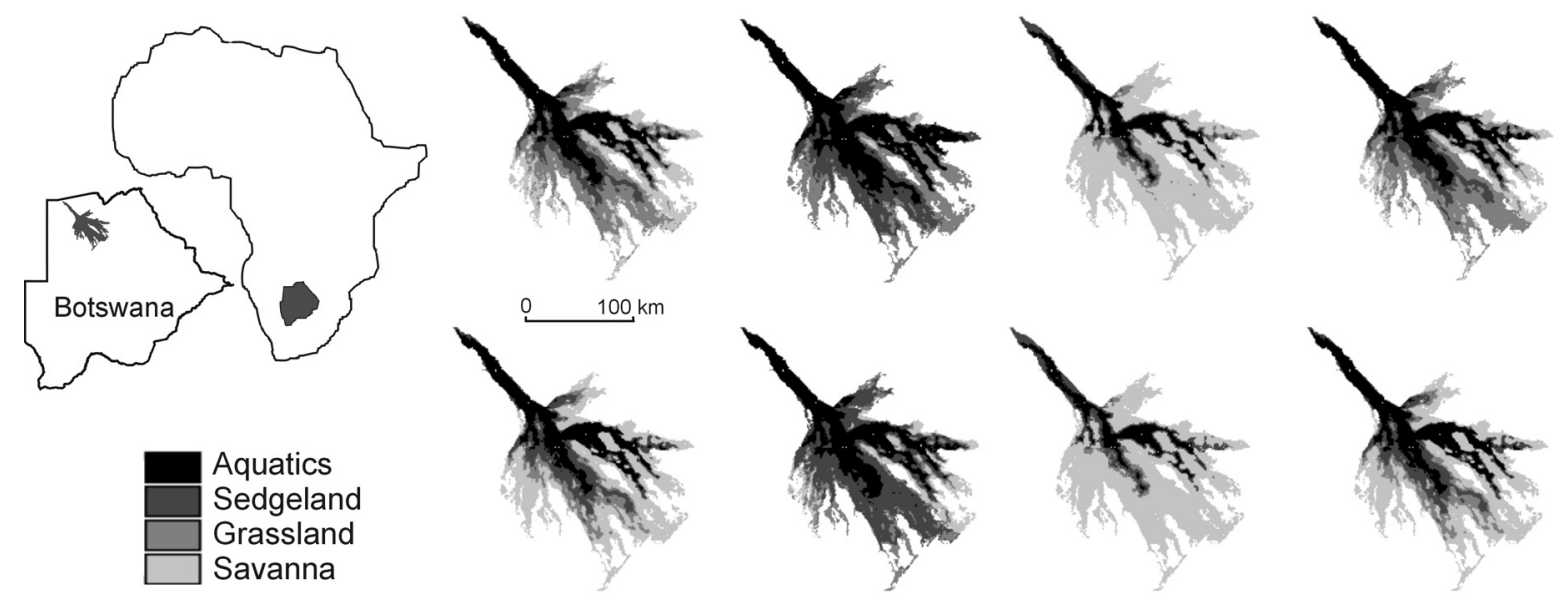

baseline

CGCM2

$\operatorname{HadCM} 3$

GFDL

Figure 4

Distribution of ecotopes for climate predictions by various GC models after year 20 (top row) and year 50 (bottom row) of the simulated time series

The results of simulations do not explicitly represent simulated future conditions. By the nature of the applied procedure the results represent conditions that would occur if the time series of rainfall and temperature observed in the past repeated itself, changed only in terms of monthly rainfall totals and mean monthly temperature. Thus, the results obtained for each GCM have to be analysed by relating them to the conditions observed in the past (1968-2002, shown as 'baseline' in Figs. 3 and 4).

\section{Baseline conditions}

Baseline simulation results presented in Fig. 3 show changes in the area of the various ecotopes. In general the pattern is such that 'dry' ecotopes such as savannah expand during drier periods of the simulated time series, at the expense of 'wet' ecotopes such as aquatic and sedge-land. In the wetter periods an opposite pattern occurs. Baseline simulation shows the disappearance of savannah and grassland ecotopes during the very wet phase between the $10^{\text {th }}$ and $13^{\text {th }}$ year of simulation (corresponding to the period of 1978-1981). This is an effect associated with the expansion of hydrological conditions supporting aquatic and sedge-land ecotopes to cover the entire modelled domain. Whether such a transformation of the ecosystem has occurred in the past is uncertain; however, there is some evidence that similar hydrological conditions have actually occurred - flows in the distal channels were perennial in the 1970s.

\section{Differences between GCMs}

The most striking feature of the results shown in Fig. 3 is the divergence of conditions simulated based on the predictions of various GCMs. Predictions by the CGCM2 model give conditions dramatically wetter than those observed in the past, the predictions of the HadCM3 model give conditions considerably drier that in the past, while those of the GFDL model give conditions similar to those observed in the past. The wetter conditions manifest themselves consistently as a larger area covered by aquatic and sedge-land vegetation communities, and a smaller area of savannah. The drier conditions are manifested by a larger area of savannah, and smaller areas of aquatic and sedge-land communities. The effects on flooded grassland community seem erratic. This can be explained by the fact that the intermittently inundated zone (with which the flooded grassland community is associated) is confined between the outer (un-floodable) boundary of the system and the zone of aquatics and sedge-lands, and as a consequence it is not proportional to the wetness of the system.

\section{Dynamics of the size of ecotopes}

The hydroperiod-vegetation model simulates different short and long-term dynamics of the areal extent of various ecotopes. The driest, savannah, changes little on a year-to-year basis, but displays a gradual increase in size during the dry phase of the simulated time series. Similarly, the areal extent of the aquatic ecotope (permanent swamp) changes relatively little on a yearto-year basis. Its gradual decline is, however, simulated for the drier part of the time series. These effects are consistent between the GCM scenarios. The sedge-land and grassland ecotopes, however, display strong year-to-year variation, with relatively minor longer-term effects, and there are differences in magnitude and direction of change between various GCM scenarios.

\section{Change in spatial distribution of ecotopes}

Maps showing distribution of ecotopes in the system under future climatic conditions simulated by the GCMs (Fig. 4) indicate that there is a change in position of ecotopes. The general pattern is that for drier conditions there is a shift of ecotope boundaries towards the Delta inlet, while for wetter conditions, ecotope boundaries shift towards distal parts of the Delta.

\section{Discussion}

The divergence of results based on future conditions predicted by the three GCMs is a striking feature of the results presented. There is large uncertainty with respect to the direction of possible climate change and its effects. This, undoubtedly, makes accounting for climate change in the management process and preparation of climate change adaptation strategies and action plans very difficult. The current tendency in assessment of future conditions is to look for convergence of the many available GCMs (IPCC, 2007). Preliminary analysis of results presented by the IPCC (2007) indicates that there is little convergence between the $21 \mathrm{GCMs}$ in the area of the Okavango Delta: 
less than $66 \%$ of models simulate drier conditions. The GCMs are more consistent in terms of future conditions in the Okavango River catchment: 66 to $76 \%$ of the IPCC models predict an increase in rainfall north of $15^{\circ} \mathrm{S}$, which is where the sources of the Okavango River are. The effects of increased rainfall can be offset by an increase in evapotranspiration accompanying an increase in air temperatures. Work is on-going to assess convergence of the hydrological effect arising from outputs of the 21 GCMs available from the US Program for Climate Model Diagnosis and Intercomparison multi-model data archive (www-pcmdi.llnl.gov), using an uncertainty analysis framework (Wolski, 2008). At this stage, however, the low level of certainty still confounds the inclusion of climate-change effects in management and planning work.

As mentioned, the results presented in this paper are preliminary and indicative only. The hydroperiod-ecotope model has not been subject to rigorous scrutiny and verification. The results cannot, therefore, be analysed in terms of absolute values of areas of various ecotopes, or their spatial distribution. The modelling, however, indicates two important effects that are directly relevant to the ecological condition of the entire Delta ecosystem, and have implications for the management of the system. Firstly, change in climatic conditions affects all ecotopes, and not only areas defined by change in 'flooding envelope'. For example, drier climatic conditions will result in a reduction in area of all inundation-dependent ecotopes: aquatics, sedgeland and flooded grassland (savannah will obviously increase in extent, as it corresponds to the area that is not subject to inundation), and not just the aquatics. Additionally, the proportion of change may not be consistent across ecotopes; that is, the reduction in extent of some ecotopes may be substantial, while the extent of other ecotopes might change less.

Secondly, change in climatic conditions results in 'migration' of ecotopes within the system: ecotopes and their boundaries may shift towards the Delta inlet, or towards the distal parts of the Delta, depending on whether respectively drier or wetter conditions are simulated. Such effects could be associated with only limited change in the extent of flooded grassland and sedge-land ecotopes.

The effect of climate change on absolute and relative extents of ecotopes is significant because while each ecotope has a distinct ecosystem function, they are all ecologically linked through material or energy flows, or the provision of ecosystem services.

For example, the aquatic ecotope is either perennially submerged or submerged for more than 11 months of every year. Within this unit, anaerobic substrate conditions result in slow nutrient cycling. The stability conferred by perennial inundation, however, permits the development of more complex trophic structure, and this ecotope constitutes an important low-water refugium for many of the fish species (Merron and Bruton, 1995), including the commercially important cichlids. It is also a critical habitat for ecologically important fauna, such as the hippopotamus (Hippopotamus amphibius), an ecosystem engineer (McCarthy et al., 1998b) and the crocodile (Crocodylus niloticus), a major carnivore. Changes in extent of this ecotope will have direct effects on the populations of these species, and their ability to utilise and affect the seasonally flooded parts of the Delta.

The flooded grassland and the sedge-land ecotopes, on the other hand, are characterised by high productivity, primarily as a result of switching redox conditions in the soils with the sequestration of nutrients and their consequent release to the vegetation resulting in very high vegetative biomass production
(Murray-Hudson, 2008). Much of this biomass sustains a very rapid growth of microbes and detritivorous consumers in the early stages of the incoming flood (Hoberg et al., 2002), enabling an up-trophic level movement of these nutrients and ultimately the export of a portion to other ecotopes. The pattern of usage of the seasonally flooded areas by fish for breeding and forage (Merron and Bruton, 1995) indicates that there is likely to be a significant return flow of nutrients from the seasonally inundated sedge-lands and flooded grasslands to the permanently flooded areas. The same seasonally flooded ecotopes are extensively utilised by grazing ungulates during the low-flood period, contributing to the extraordinarily high densities of wildlife which characterise the system during high-flood periods (SMEC, 1989).

Savannah represents floodplains that are infrequently flooded, either as a result of re-distribution of flows on a medium time scale, resulting in a successional trend towards woodland, or simply because of their topographic position in relation to sources of flooding. These old floodplains form the hinterland for the large fauna which are the resource base of the tourism industry. The relative proportions of dry and wetland ecotopes control the balance of the diversity of this fauna.

The second effect, namely that of migration of ecotopes, has more immediately apparent implications, however, for the human economy. There has been, in the past few decades, a large capital investment in physical infrastructure within the Delta: up-market lodges and the necessary infrastructure (including more than 50 airstrips) to service the US $\$ 350 \mathrm{~m} /$ a tourism industry are dispersed across the landscape. Tourist activities are dependent on the particular ecotopes accessible. Migration of ecotopes clearly has the potential to render much of this investment wasted.

\section{Summary}

In an attempt to assess effects of future climate change on the hydro-ecology of the Okavango Delta, a simple hydroperiodecotope model has been created, and linked to the existing suite of hydrological models of that system. Future climatic conditions predicted by $3 \mathrm{GC}$ models were used as an input to that suite of hydrological models and the hydroperiod-ecotope model. It was revealed that predictions of the analysed models differ not only in magnitude, but also in direction of hydrological and ecological change. Irrespective of the direction, change in climatic conditions will result in change in the extent of the Delta ecotopes, and change in their spatial distribution. Importantly, different ecotopes will be affected to varying degrees. The projected changes will have consequences for the wildlife-based management of the system. They will affect, for example, available grazing and migration/movement patterns of large herbivores, as well as fish. Such consequences can have rapid up-trophic level effects, ultimately leading to potentially substantial impacts on the economy. At this stage, however, given the uncertainty of each step in the complex process of translating modelled climate change into possible ecological change at an ecotope level, the main conclusion to be drawn is that management planning and systems should be as flexible as possible. Change will occur, that is certain, and modelling helps us to understand its potential magnitude.

\section{References}

ANDERSSON L, WILK J, TODD M, HUGHES D, EARLE A, KNIVETON D, LAYBERRY R and SAVENIJE H (2006) Impact of climate change and development scenarios on flow patterns in the Okavango River. J. Hydrol. 331 43-57. 
DINÇER T, CHILD S and KHUPE B (1987) A simple mathematical model of a complex hydrologic system - Okavango Swamp, Botswana. J. Hydrol. 93 41-65.

FLATO GM and BOER GJ (2001) Warming asymmetry in climate change simulations. Geophys. Res. Lett. 28 195-198.

GORDON C, COOPER C, SENIOR CA, BANKS HT, GREGORY JM, JOHNS TC, MITCHELL JFB and WOOD RA (2000) The simulation of SST, sea ice extents and ocean heat transport in a version of the Hadley Centre coupled model without flux adjustments. Climate Dyn. 16 147-168.

GUMBRICHT T, WOLSKI P and McCARTHY TS (2004) Forecasting the spatial extent of the annual flood in the Okavango Delta, Botswana. J. Hydrol. 190 178-191.

HOBERG P, LINDHOLM M, RAMBERG L and HESSEN DO (2002) Aquatic food web dynamics on a floodplain in the Okavango Delta, Botswana. Hydrobiol. 470 23-30.

HUGHES D, ANDERSSON L, WILK J and SAVENIJE H (2006) Regional calibration of the Pitman model for the Okavango River. J. Hydrol. 331 30-42.

IPCC (2007) Climate Change 2007: The Physical Science Basis. Contribution of Working Group I to the Fourth Assessment Report of the Intergovernmental Panel on Climate Change. S Solomon, D Qin, M Manning, Z Chen, M Marquis, KB Averyt, M Tignor and HL Miller (eds.). Cambridge University Press, Cambridge, United Kingdom and New York, NY, USA. 996 pp.

KNUTSON TR, DELWORTH TL, DIXON KW and STOUFFER RJ (1999) Model assessment of regional surface temperature trends (1949-97). J. Geophys. Res. 104 30981-30996.

MAZVIMAVI D and WOLSKI P (2006) Long-term variations of annual flows of the Okavango and Zambezi Rivers. Phys. Chem. Earth 31 944-951.

McCARTHY J, GUMBRICHT T and McCARTHY TS (2005) Ecoregion classification in the Okavango Delta, Botswana from multitemporal remote sensing. Int. J. Remote Sensing 26 4339-4357.

McCARTHY J, GUMBRICHT T, McCARTHY TS, FROST PE, WESSELS K and SEIDEL F (2004) Flooding patterns in the Okavango Wetland in Botswana, between 1972 and 2000. Ambio 7453 457.

McCARTHY TS, BLOEM A and LARKIN PA (1998a) Observations on the hydrology and geohydrology of the Okavango Delta. S. Afr. J. Geol. 101 101-117.

McCARTHY TS, ELLERY WN and BLOEM A (1998b) Some observations on the geomorphological impact of hippopotamus (Hippopota- mus amphibius L.) in the Okavango Delta, Botswana. Afr. J. Ecol. 36 44-56.

McCARTHY TS, ELLERY WN and STANISTREET IG (1992) Avulsion mechanisms on the Okavango Fan, Botswana: The control of a fluvial system by vegetation. Sedimentol. 39 779-795.

McCARTHY TS, GREEN RW and FRANEY NJ (1993) The influence of neo-tectonics on water dispersal in the northeastern regions of the Okavango swamps, Botswana. J. Afr. Earth Sci. 17 23-32.

McCARTHY TS and ELLERY WN (1997) The fluvial dynamics of the Maunachira channel system, north-eastern Okavango Swamps, Botswana. Water SA 23 115-126. http://www.wrc.org.za/downloads/ watersa/1996/July/0903\%20abstract.pdf.

MERRON GS and BRUTON MN (1995) Community ecology and conservation of the fishes of the Okavango Delta, Botswana. Environ. Biol. Fish. 43 109-119.

MURRAY-HUDSON M (2008) Personal communication. Harry Oppenheimer Okavango Research Centre, University of Botswana, Maun, Botswana.

MURRAY-HUDSON M, WOLSKI P and RINGROSE S (2006) Scenarios of the impact of local and upstream changes of climate and water use on hydro-ecology in the Okavango Delta. J. Hydrol. 331 73-84.

ODMP (2006) Okavango Delta Management Plan Project Draft Management Plan. Okavango Delta Management Plan Project, Maun, Botswana.

SMEC (1989) Ecological zoning of the Okavango Delta. Snowy Mountains Engineering Corporation, Ministry of Local Government and Lands, Gaborone, Botswana.

WOLSKI P (2008) Personal communication. Harry Oppenheimer Okavango Research Centre, University of Botswana, Maun, Botswana.

WOLSKI P, GUMBRICHT T and McCARTHY TS (2002) Assessing future change in the Okavango Delta: The use of a regression model of the maximum annual flood in a Monte Carlo simulation. In: Proc. Conf. on Environmental Monitoring of Tropical and Subtropical Wetlands. 4-8 December 2002, Maun, Botswana.

WOLSKI P and MURRAY-HUDSON M (2006) Reconstruction of 1989-2005 inundation history in the Okavango Delta, Bostwana from archival Landsat imagery. In: Proc. Globwetland Symposium. ESA-ESRIN, Frascati, Italy, 19-20 October 2006.

WOLSKI P and MURRAY-HUDSON M (2007) Detection and causal factors of change in flood distribution in the Okavango Delta, Botswana. Phys. Chem. Earth 33 157-164.

WOLSKI P, SAVENIJE H, MURRAY-HUDSON M and GUMBRICHT $\mathrm{T}$ (2006) Modelling the hydrology of the Okavango Delta, Botswana using a hybrid GIS-reservoir model. J. Hydrol. 331 58-72. 